\title{
Princípios e Protótipos Improvisacionais nas Interfaces entre o Design, a Arquitetura e a Arte Digital
}

\author{
Improvisational Principles and Prototypes in the Interface of Design, Architecture and Digital Art
}

\author{
Bruno Massara Rocha \\ Universidade Federal do Espírito Santo, Brasil \\ bmassara@gmail.com \\ Mario Victor Marques Margotto \\ Universidade Federal do Espírito Santo, Brasil \\ mvmmargotto@globo.com
}

Victor Nolasco Correa Malheiros

Universidade Federal do Espírito Santo, Brasil

malheirosvictor.vm@gmail.com

\begin{abstract}
In this paper we present final results of interface design processes developed regarding a low-tech-oriented procedures supported by computer vision and physical computing techniques. All the prototypes presented were developed in academic context in a few workshops grounded in interdisciplinary approaches between art, design and architecture. There were applied artistic creative processes such as improvisation, reprograming and post-production in the development of innovative users interfaces from the perspective of reappropriation of existent objects and its cultural nature.
\end{abstract}

Keywords: Experimental prototypes; Computer vision; Visual computing; Reprogramming; Interfaces.

\section{Introdução}

O objetivo deste documento é apresentar os resultados de três workshops realizados pelo Grupo de Pesquisa Conexão VIX, no período de 2012 e 2013 com o intuito de desenvolver objetos e ambientes interativos utilizando técnicas alternativas de aplicação da computação física e da computação visual. Estas técnicas incluem a desmontagem e reconfiguração de objetos existentes, o reaproveitamento de circuitos eletrônicos e peças variadas de hardware, a utilização de softwares de código livre ou com licenças freewares, a elaboração de algoritmos e programações interativas de modo colaborativo, tendo como meta a investigação crítica e criativa da tecnologia a partir da compreensão prática e teórica de seus fundamentos elementares.

A estrutura conceitual e programática dos workshops foi inspirada nos princípios da pós-produção, a partir de Nicholas Bourriaud, que trata da apropriação de formas culturais existentes tendo como objetivo "reinserí-las em novos enredos e narrativas" (Bourriaud, 2009). Assumida enquanto uma atividade artística de grande potencial de reconfiguração de objetos, ambientes e espaços existentes, a pós-produção foi utilizada como direcionamento para as investigações aqui propostas acerca dos possíveis desdobramentos da computação física e visual nas áreas de design e arquitetura.

O resultado desse processo foi a elaboração de objetos e ambientes, em formato de protótipos, com qualidades híbridas (analógicas e digitais), cujas características formais, funcionais, estéticas e simbólicas buscaram ser apropriadas e redefinidas pela computação física e visual. Denominamos esse processo de reprogramação, fazendo referência aos apontamentos de Bourriaud para quem a pós-produção e a arte tem a natureza de reprogramar o mundo. Entendemos que o conceito de reprogramação também estabelece vínculos importantes com a estrutura do universo digital e da computação.

\section{A pós-produção revisitada}

A pós-produção é um conceito artístico utilizado por Bourriaud para destacar obras e processos artísticos motivados mais pela recombinação de formas e objetos diferentes do que pela produção de novos. Críticos à cultura de massa e de produção serializada, ao consumo desenfreado de mercadorias, ao materialismo, ao descartável, e deificação generalizada de objetos, alguns movimentos artísticos procuraram se apropriar de objetos existentes para, como comenta Bourriaud (2009), reinterpretá-los, colocá-los em novos contextos, novas narrativas, novos itinerários culturais (Bourriaud, 2009). Se inicialmente estas apropriações e deslocamentos recuperavam objetos materiais, como Fountain (1917) de Marcel Duchamp, Campbell's Soup Cans (1962) de Andy Warhol ou ainda TV Cello 2000 (1971) de Name June Paik, com o advento das linguagens eletrônicas passou-se também a serem apropriados objetos imateriais como gravações de áudio, vídeo, fotos e programas de computador. Esse processo tornou relevante os processos de mixagem, sampleamento, deixando em evidência personagens como o hacker, o DJ, o programador, que, mais do 
que criadores formais, são criadores de encadeamentos, montagens e ligações entre formas e repertórios pré-existentes.

Abordagens com essa proposta de reapropriação e reprogramação cultural nos parecem bastante pertinentes para orientar a produção de objetos e ambientes híbridos em um contexto computacional por duas razões principais: a) reforçam qualidades fundamentais dos computadores como a variabilidade, a combinação e a transcodificação (Manovich, 2001); b) permitem surgimento de processos de inovação vinculados a referenciais culturais existentes, dando margem a soluções mais contextualizadas e próximas às interfaces já desenvolvidas.

Antes de apresentar os modelos desenvolvidos na ocasião dos workshops, é importante apresentar suscintamente os métodos computacionais utilizados para dar suporte às propostas de reprogramação e reapropriação cultural.

\section{Técnicas utilizadas: computação física e visual}

Segundo O'Sullivan e Igoe (2004), os aspectos mais provocativos de um projeto de computação física é sua capacidade de não apenas "perceber" o mundo ao seu redor, mas também alterá-lo (p.03). A transdução é a base da computação física, e consiste na conversão de sinais analógicos (temperatura, luminosidade, pressão, toque, fricção) em sinais digitais (parâmetros, valores, dados) e vice-versa. Através deste processo torna-se possível elaborar o que Ulmer e Ishii (2000) definem como interfaces tangíveis, sistemas que dão forma física para informações digitais (p.916). Em concordância com nossa intenção em desenvolver técnicas alternativas de trabalho, foram utilizados teclados USB subutilizados, que foram desmontados para a retirada de seus circuitos internos. Estes circuitos permitem realizar a transdução e servem de base para a elaboração das interfaces tangíveis.

A computação visual, por sua vez, pode ser considerada um desdobramento da computação gráfica, e pode ser encontrada em uma grande variedade de aplicações em nosso cotidiano como: OCR, fotogrametria, captura de movimentos, sistemas de vigilância, identificação de faces, impressões digitais, etc. Ela operaciona diferentes métodos de percepção visual computadorizada (visual input) através de algoritmos que "ensinam o computador a descrever o que ele vê" (Szeliski, 2010, p.5). Uma das técnicas de computação visual utilizada nos workshops é a diferenciação de frames que permite realizar análises de movimento em arquivos de vídeo digitais.

\section{Métodos Utilizados}

O método de trabalho dos workshops baseou-se nas seguintes etapas:

a) desconstrução de peças de hardware para a retirada de seus circuitos internos:

b) análise e mapeamento dos circuitos para identificação das sequências de ligação; c) apropriação de objetos físicos cotidianos para serem reprogramados e transformados em interfaces tangíveis;

d) constituição de um banco de dados digitais para servir de conteúdo a ser manipulado pelas interfaces criadas;

e) elaboração de programações utilizando software Processing voltado para a combinação dos sinais analógicos com as informações digitais

\section{Processo de trabalho}

A idéia de se pós-produzir um objeto dá margens para a incorporação de técnicas mais abertas, intuitivas e espontâneas de criação, que exploram o potencial expressivo, estético, cognitivo e funcional destes objetos. Uma das formas mais primitivas de pósprodução é o próprio ato de improvisar que, como definida por Santi, situa-se num campo entre a técnica e a espontaneidade, um momento onde ação e conhecimento encontram-se em constante reconfiguração (Santi, 2010). Improvisar é refletir de forma constante e continuada, investigando possíveis aberturas no potencial de objetos ou mesmo situações, com graus maiores de liberdade de experimentação mas sem abrir mão de uma estrutura temática que orienta e condiciona a ação improvisativa.

Em termos de processo criativo, a improvisação pode ser um espaço operacional do conceito de pensamento nômade apresentado por Deleuze (1997), uma vez que ela permite "transitar em diferentes territórios simultâneos" (Deleuze \& Guattari, 1997, p.117). Nos workshops, a ação de improvisação foi parte integrante da pós-produção dos objetos escolhidos, agenciando a combinação dos materiais disponíveis para sua remontagem e recombinação. Alguns deles como peças de hardware, elementos metálicos, fios e cabos, utilizados para refazer contatos elétricos e estruturar os novos objetos foram retirados de peças descartadas e subutilizadas.

Ao contrário do que é normalmente considerado, o improviso não é uma ação aleatória e desregrada, mas apoia-se diretamente em estruturas subjacentes pré-definidas, trajetos, temas, que orientam e coordenam o desenrolar processo criativo.

\section{Descrição dos objetos produzidos}

USBook: O protótipo denominado USBook é uma interface tangível híbrida elaborada a partir de um pequeno caderno de anotações ao qual foram incorporados circuitos eletrônicos visando dotá-lo de uma capacidade narrativa ampliada, mas mantendo a referência formal, estética e, acima de tudo, a gestualidade na manipulação das folhas de um diário. Ao caderno foi incorporado um circuito interno de teclado de computador com conexão USB. Fios de cobre e clipes metálicos foram instalados nas folhas do caderno, fazendo com que seu movimento gerasse inputs elétricos que, captados pelo computador, comandavam vídeos, sons e sequências de imagens. Este objeto permitiu explorar a singularidade do ato de leitura de um livro associado ao dinamismo da linguagem audiovisual digital. 


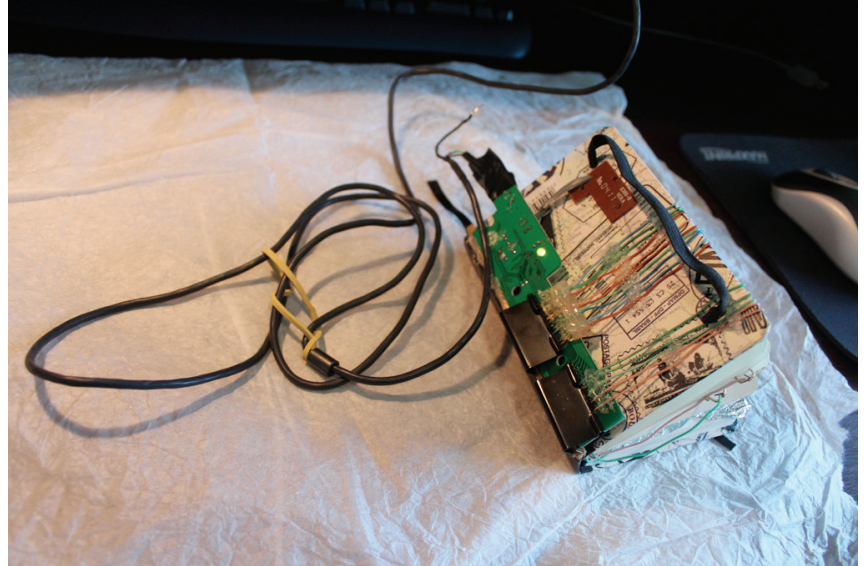

Figura 1: Protótipo USBook. Vídeo disponível em http://vimeo.com/71752266

Digital Box: Neste objeto foi investigado o potencial da computação visual em criar interfaces tangíveis a partir de webcams. Algoritmos de computação visual permitem transformar sistemas de captura de imagens em sensores que, no caso deste protótipo, detecta e codifica os movimentos das mãos ao tocarem em uma superfície translúcida. Uma caixa preta de papelão com uma tampa translúcida de papel vegetal armazena uma webcam em sua base, direcionando sua lente para a parte superior, de modo a capturar toda a superfície da tampa. Ao deslizarmos o dedo sobre a superfície externa da caixa, a webcam captura e processa as sombras projetadas pelos dedos gerando assim um efeito touchscreen numa simples folha de papel vegetal.

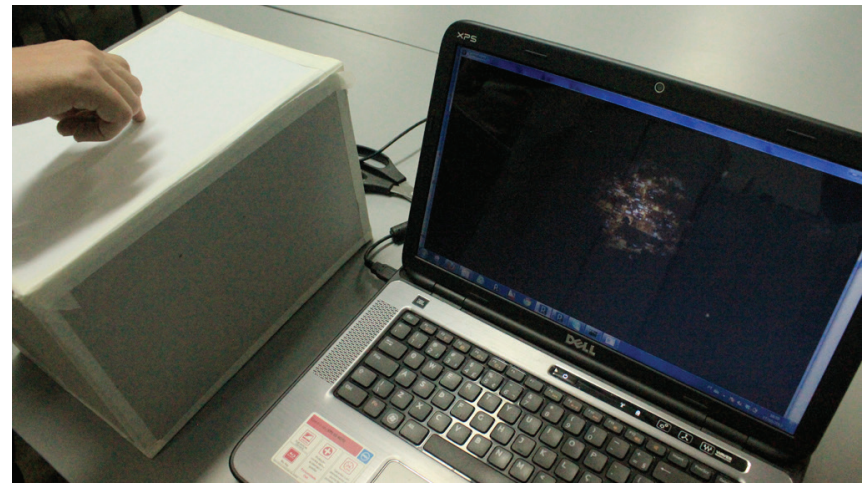

Figura 2: Protótipo Digital Box. Vídeo disponível em http://vimeo.com/75964902

Grafitti Digital: Tomando como referência a arte do grafitti, este protótipo baseou-se em princípios da computação visual para reprogramar um recipiente de desodorante e torná-lo uma interface interativa capaz de controlar projeções de imagens em grandes superfícies. À lata de desodorante foi incorporada internamente uma bateria de 3 volts e dois fios condutores ligados a uma lâmpada LED vermelha que fica exposta através de uma abertura existente na tampa da lata. Quando pressionamos a válvula do desodorante a lâmpada se acende. Algoritmos de captura de imagem e reconhecimento de cores desenvolvidos no
Processing rastreiam o movimento do LED e criam rastros coloridos à medida que pressionamos a válvula do desodorante. $\mathrm{O}$ modo de operação deste protótipo apropria-se da gestualidade do ato de grafittar uma parede, recriando digitalmente uma linguagem artística extremamente significativa a partir de novas relações simbólicas e tecnológicas.

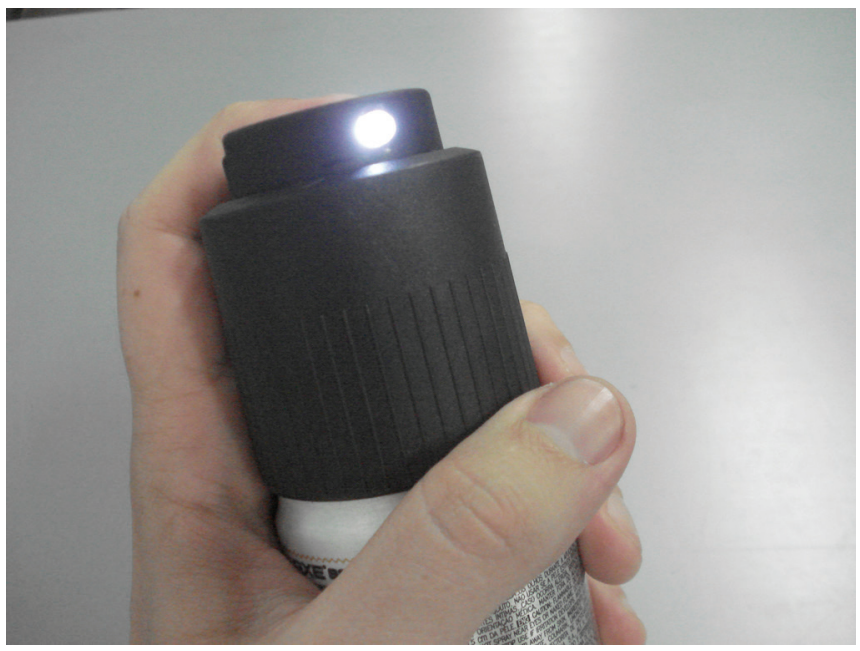

Figura 3: Protótipo Grafitti Digital

Carimbo: Este protótipo apropriou-se do ato de carimbar superfícies para elaborar um mecanismo que permite produzir inputs digitais a partir do contato do carimbo com sua respectiva almofada. A almofada teve sua tinta removida e o seu lugar instalado um circuito de teclado de computador ligado à superfícies de papel alumínio. No carimbo foram implantadas moedas e fios de cobre que, ao entrar em contato com a superfície metálica da almofada enviam sinais elétricos ao computador. O gesto de carimbar superfícies, imprimir a elas novos códigos e signos, foi recuperado e reprogramado com a tecnologia digital. Neste caso, podem ser "impressos" sons, imagens, vídeos e animações a uma superfície digital ou projeção.

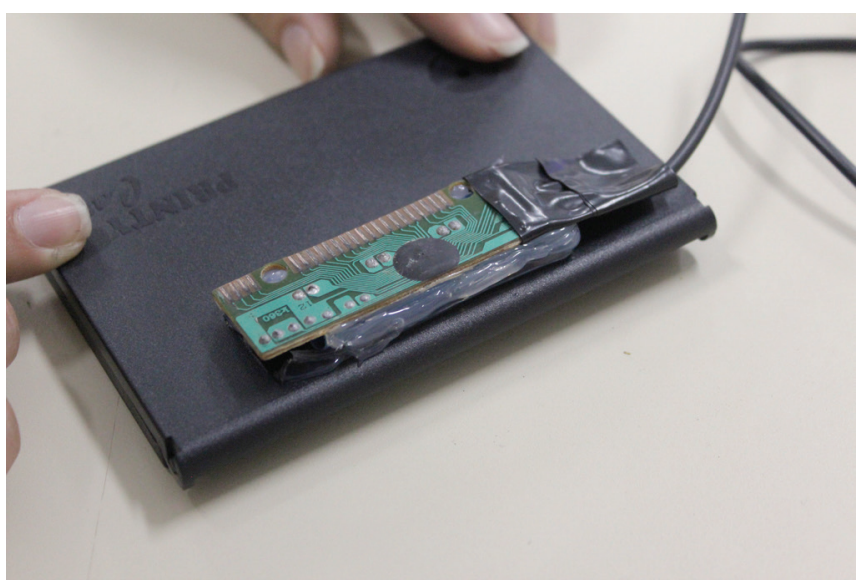

Figura 4: Protótipo Carimbo. Vídeo disponível em http://vimeo.com/75950130 
Tablet Low-tech: Neste experimento as referências principais foram os tables e mesas digitalizadoras, equipamentos de uso massivo na atualidade por designer e arquitetos. No entanto, o exercício de construção deste protótipo utilizou uma caixa de papelão e uma caneta Bic 4 cores para recriar de modo infinitamente mais simples esta nova relação entre dispositivos manuais digitais e superfícies sensíveis voltadas para representação. A caneta teve sua carga de tinta removida e em seu interior incorporados fios de cobre conectados à ponta metálica da caneta. A superfície sensível é constituída por lâminas de alumínio que são igualmente conectadas a um circuito reaproveitado de computador com ligação USB. O contato das quatro pontas da caneta na superfície de alumínio produz inputs de informação que são enviados ao computador permitindo gerar transições de imagens, efeitos visuais, sonoros, simulando uma interface gráfica de representação aos moldes das mesas digitalizadoras. Trata-se aqui principalmente de recriar experimentalmente modos alternativos de manipulação de dados digitais, incorporando referências existentes, e abrindo caminhos para inúmeras reflexões tangentes acerca dos gestos, dos atos, das ações e linguagens.

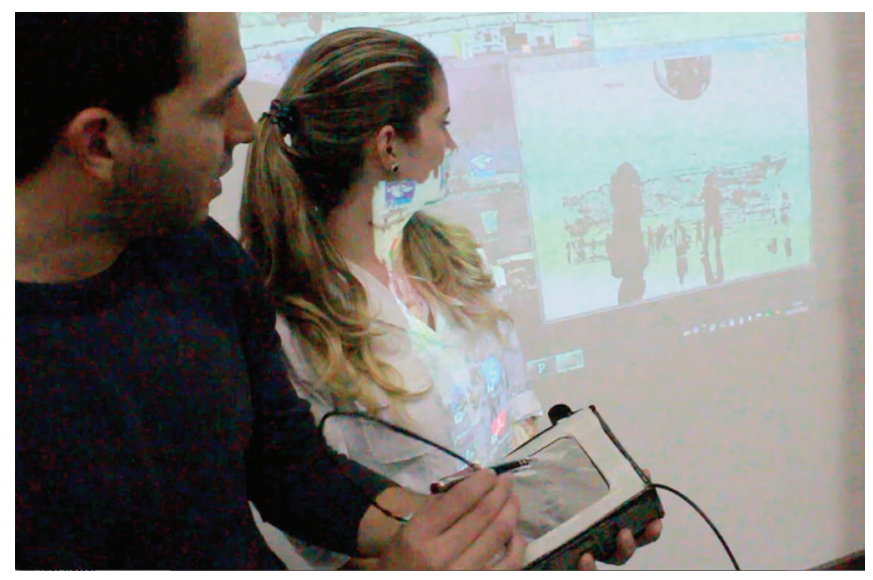

Figura 5: Protótipo Tablet Low-Tech. Vídeo disponível em http://vimeo.com/75950131

Circuitos de Lego: A intenção em utilizar peças de Lego para elaborar interfaces tangíveis foi a motivação maior deste protótipo. O objeto associa as unidades de Lego com os circuitos eletrônicos, fios e contatos metálicos, experimentando uma linguagem de composição "quebra-cabeças" para criar uma interface original de manipulação de informações digitais. As peças de Lego foram combinadas de modo que ao se encaixarem são produzidos contatos elétricos e enviados inputs de informação para um computador. Este objeto permite uma reflexão acerca do potencial de combinação das peças Lego com possíveis combinações de efeitos audiovisuais e gráficos digitais.

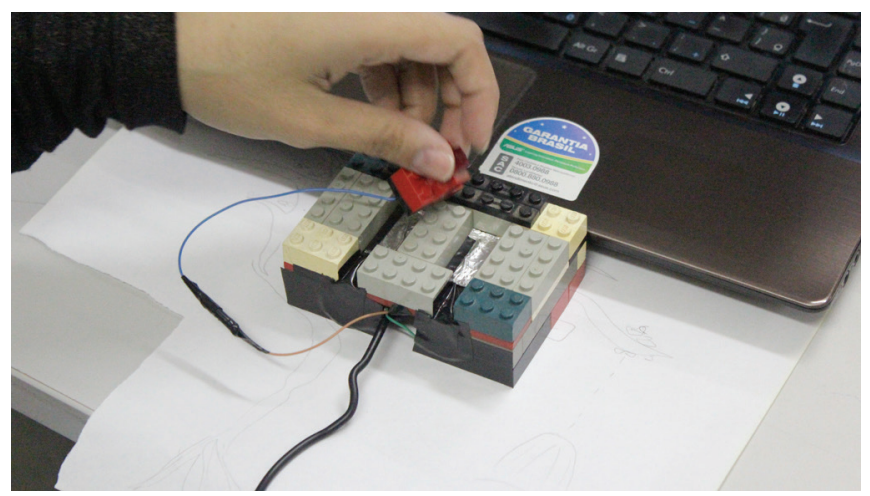

Figura 6: Protótipo Circuitos de Lego. Vídeo disponível em http://vimeo.com/75962183

\section{Análise dos Resultados}

Cada um dos objetos produzidos possui uma qualidade processual que é relevante em termos de inovação pelas seguintes razões: a) exercitaram a capacidade de apropriação de objetos existentes, demandando uma análise multiescalar de qualidades: simbólicas, culturais, gestuais e técnicas, aproximando projeto e contexto; b) demandaram um pensamento improvisacional que rompe com um processo criativo linear rumo a métodos transversais e circulares de resolução de problemas em tempo real; c) proporcionaram uma apropriação ao mesmo tempo aprofundada, mas periférica da tecnologia, incorporando suas qualidades sem deificações, como um recurso intermediário que pode ser criticado e reprogramado em prol de objetivos mais complexos e ampliados; d) ofereceram um ambiente de proximidade entre arte, design e arquitetura, criando um campo prático interdisciplinar de investigação aberto a novas sensibilidades entre estas áreas, que acreditamos serem fundamentais para processos de inovação.

\section{Agradecimentos}

Nós gostaríamos de agradecer a todos os membros do Grupo de Pesquisas Conexão Vix da Universidade Federal do Espírito Santo e a FAPES (Fundação de Amparo à Pesquisa do Espírito Santo) pelo apoio financeiro.

\section{Referências}

Bourriaud, N. (2009). Pós-produção: como a arte reprograma o mundo contemporâneo. São Paulo: Martins Fontes.

Manovich, L. (2001). The language of new media. Cambridge: MIT Press.

Deleuze, G., \& Guattari, F. (1997). Mil Platôs: capitalismo e esquizofrenia (Vol. 5). São Paulo: Ed. 34.

O'Sullivan, D., \& Igoe, T. (2004). Physical Computing: sensing and controlling the physical world with computers. Boston: Thomson.

Santi, M. (2010). Improvisation: between technique and spontaneity. Newcastle: Cambridge Scholars.

Szeliski, R. (2010). Computer Vision: algorithms and applications. In Springer (Eds.) Available from http://szeliski.org/Book

Ullmer, B., \& Ishii, H. (2000). Emerging Frameworks for tangible user interfaces. IBM Systems, 39(3\&4), 17. 